\title{
Multilocus sequence typing of Cronobacter sakazakii and Cronobacter malonaticus reveals stable clonal structures with clinical significance which do not correlate with biotypes
}

\author{
Adam Baldwin ${ }^{1}$, Michael Loughlin ${ }^{2}$, Juncal Caubilla-Barron², Eva Kucerova ${ }^{2}$, \\ Georgina Manning ${ }^{2}$, Christopher Dowson ${ }^{1}$ and Stephen Forsythe*2
}

\author{
Address: ${ }^{1}$ Biological Sciences Department, University of Warwick, Gibbet Hill Road, Coventry, CV4 7AL, UK and ${ }^{2}$ School of Science and \\ Technology, Nottingham Trent University, Clifton Lane, Nottingham, NG11 8NS, UK \\ Email: Adam Baldwin - Adam.Baldwin@warwick.ac.uk; Michael Loughlin - Michael.loughlin@ntu.ac.uk; Juncal Caubilla- \\ Barron - Juncal.caubillabarron@ntu.ac.uk; Eva Kucerova - Eva.kucerova@ntu.ac.uk; Georgina Manning - Georgina.manning@ntu.ac.uk; \\ Christopher Dowson - C.G.Dowson@warwick.ac.uk; Stephen Forsythe* - Stephen.forsythe@ntu.ac.uk \\ * Corresponding author
}

Published: 23 October 2009

BMC Microbiology 2009, 9:223 doi:10.1 I86/147|-2180-9-223
Received: 15 July 2009

Accepted: 23 October 2009

This article is available from: http://www.biomedcentral.com/I47I-2180/9/223

(C) 2009 Baldwin et al; licensee BioMed Central Ltd.

This is an Open Access article distributed under the terms of the Creative Commons Attribution License (http://creativecommons.org/licenses/by/2.0), which permits unrestricted use, distribution, and reproduction in any medium, provided the original work is properly cited.

\begin{abstract}
Background: The Cronobacter genus (Enterobacter sakazakii) has come to prominence due to its association with infant infections, and the ingestion of contaminated reconstituted infant formula. C. sakazakii and C. malonaticus are closely related, and are defined according their biotype. Due to the ubiquitous nature of the organism, and the high severity of infection for the immunocompromised, a multilocus sequence typing (MLST) scheme has been developed for the fast and reliable identification and discrimination of $C$. sakazakii and $C$. malonaticus strains. It was applied to 60 strains of $C$. sakazakii and 16 strains of $C$. malonaticus, including the index strains used to define the biotypes. The strains were from clinical and non-clinical sources between $195 \mathrm{I}$ and 2008 in USA, Canada, Europe, New Zealand and the Far East.
\end{abstract}

Results: This scheme uses 7 loci; atpD, fusA, glnS, gltB, gyrB, infB, and pps. There were 12 sequence types (ST) identified in C. sakazakii, and 3 in C. malonaticus. A third (22/60) of C. sakazakii strains were in ST4, which had almost equal numbers of clinical and infant formula isolates from I95I to 2008. ST8 may represent a particularly virulent grouping of $C$. sakazakii as $7 / 8$ strains were clinical in origin which had been isolated between 1977 - 2006, from four countries. C. malonaticus divided into three STs. The previous Cronobacter biotyping scheme did not clearly correspond with STs nor with species.

Conclusion: In conclusion, MLST is a more robust means of identifying and discriminating between $C$. sakazakii and $C$. malonaticus than biotyping. The MLST database for these organisms is available online at http://pubmlst.org/cronobacterl.

\section{Background}

The genus Cronobacter is composed of Gram-negative, facultative anaerobic rods, which are members of the Entero- bacteriaceae Family. It was formerly known as Enterobacter sakazakii and was divided into 15 biotypes [1]. The biotyping scheme was based on Voges-Proskauer, methyl red, 
indole, ornithine decarboxylase, motility, reduction of nitrate to nitrite, production of gas from D-glucose, malonate utilization and production of acid from myoinositol and dulcitol. Based on 16S rDNA sequence analysis, we extended this further to 16 biotypes $[2,3]$ which has contributed to the recent taxonomic revisions. Initially the Cronobacter genus was composed of 4 species; $C$. sakazakii, C. turicensis, C. muytjensii, C. dublinensis, plus a possible fifth species [4]. More recently, the species $C$. malonaticus sp. nov. was proposed [5]. This was initially regarded as a subspecies of $C$. sakazakii as the two species could not be distinguished according to 16S rDNA sequence analysis however DNA-DNA hybridisation studies revealed a $<70 \%$ DNA relatedness. Consequently $C$. sakazakii consists of biotypes $1-4,7 \& 8,11 \& 13$, and $C$. malonaticus contains biotypes 5, 9 and 14 [5].

Cronobacter spp. have come to prominence due to their association with infant infections, and cases linked to the ingestion of contaminated reconstituted infant formula [6-8]. However not all cases have been linked to formula ingestion. The organism is ubiquitous in the environment (water and soil) and food $[9,10]$.

Cronobacter spp. cause infections across all age groups [11]. However neonates, particularly those of low-birth weight, are the major identified group at risk with a high mortality rate $[6,11]$. The organism is a rare cause of neonatal meningitis, necrotising enterocolitis (NEC) and sepsis. A number of outbreaks of C. sakazakii have been reported in neonatal intensive care units around the world [12-16]. The International Commission for Microbiological Specifications for Foods (2002) [17] has ranked Cronobacter spp. as 'severe hazard for restricted populations, life-threatening or substantial chronic sequelae or long duration'. The FAO/WHO $[6,7,11]$ have undertaken three risk assessments of the organism in powdered infant formula, and the WHO [18] have published recommended procedures for the reconstitution of powdered infant formula to reduce the risk of infection to neonates. Together with the ubiquitous nature of the organism, and the high severity of infection for the immunocompromised, there is a need for a technique that enables fast and reliable classification and identification of Cronobacter strains worldwide.

Selected strains of Cronobacter spp. have been shown to invade human intestinal cells, replicate in macrophages, and invade the blood brain barrier $[19,20]$. Based on the clinical outcome of different pulsetypes during a neonatal intensive care unit outbreak it was proposed that certain types of C. sakazakii are particularly virulent $[16,20]$. Whether the virulence was linked to a particular genotype or phenotype warranted further investigation.
16S rDNA sequences can be useful to determine phylogenies between distantly related Enterobacteriaeceae [21]. However it is less discriminatory and unclear for more closely related organisms. An alternative to rDNA sequence analysis is the partial sequencing of proteinencoding genes. Additionally, for determining phylogenetic relationships, sequence data from more than one gene should be used to reduce the possibly of ambiguities caused by genetic recombination or specific selection $[21,22]$. A number of such genes have been used as phylogenetic markers for members of the Enterobacteriaceae. Genes which have been analysed include $r p o B, g y r B, m d h$, inf $\mathrm{B}$ and recA $[23,24]$. These results can be more reliable for species identification and determining intra- and intergeneric relationships than $16 \mathrm{~S}$ rDNA gene sequencing. Recently, Kuhnert et al. [25] used three loci $(r e c N, r p o A$ and $t h d F$ ) for 30 species of Enterobacteriaceae including Cronobacter spp. Whereas our work is focussed on a higher resolution analysis of C. sakazakii and C. malonaticus using 7 loci. The genes under study were atpD, fusA, glnS, gltB, $g y r B$, infB, and $p p s$. These genes encode for ATP synthase B subunit, elongation factor EF-2, glutamyl-tRNA synthetase, glutamate synthase large subunit, type IIA topoisomerase, initiation translation factor 2 and phosphoenol pyruvate synthase, respectively. These were compared with the previous biotyping scheme for Cronobacter spp. and also considered the source and isolation date of the strains.

\section{Results}

\section{Development of the Cronobacter MLST scheme}

Several criteria were used in the selection of all potential loci. Genes included were those encoding for putative housekeeping products necessary for biological roles in DNA repair, replication and amino acid biosynthesis. Genes that were either a) located near to or b) implicated as being, putative virulence factors and mobile elements were avoided as these may come under greater selective evolutionary pressures than other genes. The selected loci were distributed as much as possible across the chromosome to ensure that each locus was genetically unlinked. Each gene fragment was also required to be approximately $500 \mathrm{bp}$ in length to facilitate the design of universal nested primers for each locus preferably in conserved flanking regions around a variable central core. Using these criteria, genes were selected and the chromosomal locations of all these loci were confirmed by bioinformatic analysis of the C. sakazakii BAA-894 genome sequence (Genbank accession number $\underline{\mathrm{CP} 000785}$ ).

The genes selected for the MLST scheme (atpD, fusA, glnS, gltB, gyrB, infB and $p p s$ ) are shown in Table 1 along with putative gene products, gene sizes, primers and location within the C. sakazakii ATCC BAA-894 genome. 
Table I: Oligonucleotide nested primer sequences for the amplification and sequencing of the seven loci from genes in $C$. sakazakii and C. malonaticus, with gene number and location of genes within the genome of the $C$. sakazakii strain ATCC BAA-894.

\begin{tabular}{|c|c|c|c|c|c|}
\hline \multirow[b]{2}{*}{$\begin{array}{c}\text { Gene } \\
\text { (Gene label) }\end{array}$} & \multirow[b]{2}{*}{$\begin{array}{l}\text { Putative Gene } \\
\text { Product }\end{array}$} & \multirow[b]{2}{*}{$\begin{array}{l}\text { Chromosome location } \\
\text { (bp) }\end{array}$} & \multirow[b]{2}{*}{ Gene Size (bp) } & \multicolumn{2}{|c|}{ Locus Primers $\left(5^{\prime} \rightarrow 3^{\prime}\right)$} \\
\hline & & & & Amplification & Sequencing \\
\hline$a t p D$ & ATP synthase $\beta$ chain & $3,689,177-3,690,559$ & 1,382 & $\begin{array}{c}\text { CGACATGAAAGGCGA } \\
\text { CAT }\end{array}$ & $\begin{array}{c}\text { CGAAATGACCGACTC } \\
\text { CAA }\end{array}$ \\
\hline (ESA_04006) & & & & $\begin{array}{c}\text { TTAAAGCCACGGATG } \\
\text { GTG }\end{array}$ & $\begin{array}{c}\text { GGATGGCGATGATGT } \\
\text { CTT }\end{array}$ \\
\hline fusA & Elongation factor & $3,275,843-3,277,957$ & 2,114 & $\begin{array}{c}\text { GAAACCGTATGGCGT } \\
\text { CAG }\end{array}$ & $\begin{array}{c}\text { GCTGGATGCGGTAAT } \\
\text { TGA }\end{array}$ \\
\hline (ESA_0440I) & & & & $\begin{array}{c}\text { AGAACCGAAGTGCAG } \\
\text { ACG }\end{array}$ & $\begin{array}{c}\text { CCCATACCAGCGATG } \\
\text { ATG }\end{array}$ \\
\hline$g \ln S$ & Glutaminyl-tRNA & $660,368-662,035$ & 1,667 & $\begin{array}{c}\text { GCATCTACCCGATGT } \\
\text { ACG }\end{array}$ & $\begin{array}{c}\text { GGGTGCTGGATAACA } \\
\text { TCA }\end{array}$ \\
\hline (ESA_02658) & synthetase & & & $\begin{array}{l}\text { TTGGCACGCTGAACA } \\
\text { GAC }\end{array}$ & $\begin{array}{c}\text { CTTGTTGGCTTCTTCA } \\
\text { CG }\end{array}$ \\
\hline$g \mid t B$ & Glutamate synthase & $3,538,713-3,542,921$ & 4,208 & $\begin{array}{c}\text { CATCTCGACCATCGC } \\
\text { TTC }\end{array}$ & $\begin{array}{c}\text { GCGAATACCACGCCT } \\
\text { ACA }\end{array}$ \\
\hline (ESA_03606) & large subunit & & & $\begin{array}{c}\text { CAGCACTTCCACCAG } \\
\text { CTC }\end{array}$ & $\begin{array}{c}\text { GCGTATTTCACGGAG } \\
\text { GAG }\end{array}$ \\
\hline gyrB & DNA gyrase B & $3,719,848-3,722,262$ & 2,414 & $\begin{array}{c}\text { TGCACCACATGGTAT } \\
\text { TCG }\end{array}$ & $\begin{array}{c}\text { CTCGCGGGTCACTGT } \\
\text { AAA }\end{array}$ \\
\hline (ESA_03973) & & & & $\begin{array}{c}\text { CACCGGTCACAAACT } \\
\text { CGT }\end{array}$ & $\begin{array}{c}\text { ACGCCGATACCGTCT } \\
\text { TTT }\end{array}$ \\
\hline $\operatorname{infB}$ & Translation initiation & $4,|39,05|-4,|4|, 762$ & 2,711 & $\begin{array}{c}\text { GAAGAAGCGGTAATG } \\
\text { AGC }\end{array}$ & $\begin{array}{c}\text { TGACCACGGTAAAAC } \\
\text { CTC }\end{array}$ \\
\hline (ESA_0356I) & factor IF-2 & & & $\begin{array}{c}\text { CGATACCACATTCCA } \\
\text { TGC }\end{array}$ & $\begin{array}{c}\text { GGACCACGACCTTTA } \\
\text { TCC }\end{array}$ \\
\hline pps & Phosphoenol-pyruvate & $1,218,599-1,220,977$ & 2,378 & $\begin{array}{l}\text { GTCCAACAATGGCTC } \\
\text { GTC }\end{array}$ & $\begin{array}{c}\text { ACCCTGACGAATTCT } \\
\text { ACG }\end{array}$ \\
\hline (ESA_02102) & synthase & & & $\begin{array}{c}\text { CAGACTCAGCCAGGT } \\
\text { TTG }\end{array}$ & $\begin{array}{c}\text { CAGATCCGGCATGGT } \\
\text { ATC }\end{array}$ \\
\hline
\end{tabular}

\section{Allelic variation}

Novel sequence information for all seven loci was obtained from a collection of 60 C. sakazakii and 16 C. malonaticus strains. To assess the performance of the MLST scheme, Cronobacter strains were selected to be representative of the different biotypes (most of which were previously derived in an earlier study [3]), and were also distributed both temporally and geographically in terms of their isolation (See Additional file 1). In silico sequence data was also obtained for all the loci from C. sakazakii strain ATCC BAA-894 (Accession No. CP000785), Citrobacter koseri strain ATCC BAA-895 (Accession No. CP000822), and Enterobacter species strain 683 (Accession No. $\mathrm{CP000653}$ ). The latter strain sequence data was used to root the data set. The seven alleles obtained for the C. sakazakii genome reference strain BAA-894 were identical to the online genome sequence ( $\mathrm{CP000785}$ ). 
The mean allele length was $434 \mathrm{bp}$ for the scheme and ranged between $363 \mathrm{bp}(\mathrm{gln} S)$ and $507 \mathrm{bp}(\mathrm{gltB})$ in length (Table 2). All alleles within a particular locus were found to be of an identical length for all Cronobacter strains examined. Nucleotide sequence diversity at all seven loci is shown in Table 2 . The proportion of variable sites varied from $10.8 \%$ ( $a t p D)$ to $27.6 \%$ ( $g y r B$ ) which extended over the whole section of the sequenced allele.

Allele variation is not necessarily equally likely at every nucleotide of each locus. If a locus does not have a role affected by a selective pressure (such as antibiotic exposure) then nucleotide substitutions would frequently not be expected to change the amino acid sequence (synonymous) as changes are likely to be eliminated by purifying selection. By calculating the $d_{N} / d_{S}$ ratio (non-synonymous substitutions to synonymous substitutions) the degree of selection operating on each locus can be estimated. The $d_{N} / d_{S}$ ratio for all seven loci within Cronobacter strains was found to be significantly less than 1 , ranging from 0.006 $(a t p D)$ to 0.079 (infB) (Table 2), indicating that no strong positive selective pressure was present at any of the loci selected, validating their suitability for inclusion in the MLST scheme.

\section{Assignment of allele and sequence types}

The number of different alleles resolved from this Cronobacter MLST scheme at each locus ranged from $11(\mathrm{gltB})$ to 15 (pps) alleles. The mean number of allele types per locus was found to be 13.4, providing the potential to distinguish $>7 \times 10^{10}$ different genotypes and also making it highly unlikely to obtain identical sequence types (ST) by chance.

For the development of the MLST scheme, it was important to use a diverse collection of strains to obtain primarily different STs based upon known 16S rRNA gene sequencing and biotype to validate the scheme's effectiveness across the two Cronobacter species. For each unique allelic profile in the order $a t p D, f u s A, g l n S, g l t B, g y r B$, inf $B$ and $p p s$, a unique ST was designated; See Additional file 1.
A total of 17 STs were found for the 78 strains examined (See Additional file 1$) ; 12$ STs for for C. sakazakii $(\mathrm{n}=60)$, 3 C. malonaticus $(\mathrm{n}=16), 1$ Cit. koseri $(\mathrm{n}=1)$ and 1 Enterobacter sp. $638(\mathrm{n}=1)$. The sequences of each allele type at all seven loci, along with the allelic profiles and sequence types used for the multilocus sequence sequence analysis (MLSA) of the Cronobacter strains examined are available at http://pubmlst.org/cronobacter/.

The close genetic relationship between C. sakazakii and $C$. malonaticus was evident in that atpD allele 3 was identified both in C. sakazakii (ST3, ST17) and C. malonaticus (ST10). Apparently 'species specific' alleles were found across different STs e.g. the GlnS allele 3 was identified in C. sakazakii ST 3, 4,15 and 16, fusA allele 1 was in C. sakazakii ST1, 4, and 14, and three C. malonaticus STs had fusA allelic profile 7, and ST7 and ST10 had gltB allelic profile 7.

\section{Comparison of sequence type with source and biotype}

In total 60 C. sakazakii and 16 C. malonaticus strains were analysed. Most strains analysed were associated with previous publications (See Additional file 1). The earliest isolate (NCIMB 8272) was from a can of dried milk powder, which was deposited in the culture collection in 1951, and the earliest clinical isolate (NCTC 9238) was deposited in 1953 [1].

C. sakazakii ST1 contained infant formula isolates from 1988-2003 from Russia, Netherlands, USA and UK. It included the ATCC BAA-894 strain from the Tennesse NICU outbreak [13] which has been sequenced (Accession number $\underline{\mathrm{CP} 000785}$ ). Two strains were from milk powder and faeces. There were no known clinical outbreak isolates in ST1. C. sakazakii ST14 was a single strain from infant formula in France (1994) [16]. This ST varied by just a single nucleotide polymorphism from ST1 with respect to the pps locus. C. sakazakii ST3 strains were from infant formula, follow up formula, weaning food, and neonatal enteral feeding tubes. The strains were from 1988-2008, and were isolated in the Netherlands, UK, and Korea. There were no known clinical isolates, however

Table 2: Analysis of the seven MLST loci in the Cronobacter strains sampled.

\begin{tabular}{|c|c|c|c|c|c|}
\hline Gene & Size (bp) of fragment analysed & No. of alleles & No. of polymorphic sites & $\begin{array}{l}\text { Proportion of fragment as polymorphic } \\
\text { sites (\%) }\end{array}$ & $d_{N} / d_{S}$ \\
\hline$a t p D$ & 390 & 12 & 42 & 10.8 & 0.006 \\
\hline fusA & 438 & 12 & 69 & 15.8 & 0.061 \\
\hline$g \ln S$ & 363 & 12 & 72 & 19.8 & 0.062 \\
\hline$g l t B$ & 507 & 11 & 118 & 23.3 & 0.059 \\
\hline gyrB & 402 & 13 & 111 & 27.6 & 0.055 \\
\hline infB & 441 & 12 & 87 & 19.7 & 0.079 \\
\hline Pps & 495 & 15 & 123 & 24.8 & 0.033 \\
\hline
\end{tabular}


there is no information available about the source for $C$. sakazakii strain ATCC 12868 in the culture collection.

C. sakazakii ST4 was the major (22/60) sequence type among the isolates. It contained almost equal numbers of clinical $(\mathrm{n}=9)$ and infant formula $(\mathrm{n}=7)$ isolates. This ST also included the Betty Hobbs 1951 isolate from a can of dried milk (NCIMB 8272) [1]. In contrast, strains in C. sakazakii ST8 were predominantly (7/8) clinical isolates from USA, Canada, and Czech Republic. The isolation dates ranged from 1977-2003, and included the C. sakazakii type strain (NCTC $11467^{\mathrm{T}}$ ). The remaining strain was isolated in 2006 from infant formula in France. C. sakazakii ST12 included 5 strains from UK, USA, France and Czech Republic, at least 3 of which were clinical in origin.

C. malonaticus ST7 contained 11 strains which were primarily clinical in origin from the Czech Republic, isolated between 1977 and 2004. C. malonaticus ST11 contained 3 clinical strains from the Czech Republic, biotypes 2a, 14a, and 13b which were isolated in 1983 [30]. C. malonaticus ST10 was composed of two strains from chinese herbs which were both isolated in 2005 .

Biotypes did not always correspond with sequence types or Cronobacter species (See Additional file 1). For example, biotype 2 was primarily distributed over C. sakazakii ST1 and 3, with two other strains in ST4. The index strain for biotype 2a was in C. malonaticus ST11, and a second strain was in C. sakazakii ST12. Biotype 1 was in C. sakazakii ST4, $8,13,15,17$ and 18. C. malonaticus is defined as biotypes 5, 9 and 14 [5]. However biotype 5 was in C. malonaticus ST7 and 10, and C. sakazakii ST16. Biotype 9 was only in $C$. malonaticus ST7. Whereas biotype 14 and 14 a were in $C$. malonaticus ST7, and ST11. Biotypes 2a, 4a, 13a, and 13b are conventionally assigned to C. sakazakii [3]. However, C. malonaticus ST7 included the index strains for biotypes 4a and 13a, and C. malonaticus ST11 included the index strains for biotypes $2 \mathrm{a}$ and $13 \mathrm{~b}$.

\section{Relationships of C. sakazakii, C. malonaticus, Cit. koseri and Enterobacter sp. 638 using concatenated nucleotide sequences}

In order to assess all the loci together in one tree, concatenated nucleotide sequences were used. Concatenated nucleotide sequences $(3,036 \mathrm{bp})$ for the 15 Cronobacter STs, Cit. koseri and Enterobacter sp. 638 were analysed using the UPGMA method (Figure 1). The Cronobacter species were fully resolved, falling into distinctive clusters of strains. The Cronobacter species were clearly separated from the Enterobacter sp. strain 638 and also by a lesser extent from the Cit. koseri strain (100\% bootstraps). C. sakazakii and C. malonaticus separated from each other at $2.6 \%$ divergence (100\% bootstrap value), and from Citro- bacter koseri at $13 \%$ divergence. Figure 1 also shows the distribution of biotypes across the sequence types.

\section{Analysis of recombination among $C$. sakazakii}

Bacteria existing as clonal populations evolve diversity by the accumulation of point mutations, while non-clonal populations evolve more through recombination within or between species. In this study identical alleles were found within species and between the two Cronobacter species (See Additional file 1).

Evidence for clonal or recombining populations can be estimated by assessing the level of linkage between alleles at different loci around the chromosome. The index of association $\left(I_{A}\right)[34]$ measures the extent of linkage. An $I_{A}$ not significantly greater than zero after 1,000 computer randomizations would suggest that a single species population (monophyletic) is in linkage equilibrium (freely recombining), while a population with an $I_{A}$ significantly greater than zero $(p<0.001)$ is considered to be in linkage disequilibrium (clonal). C. sakazakii examined had an $I_{A}$ value of 0.28 ( $\mathrm{p}$ value $<0.01$ ) and therefore indicates a more clonal that freely recombining population. Further analysis will be undertaken as part of a subsequent study, along with other Cronobacter spp..

\section{Discussion and Conclusion}

The diversity of Enterobacter sakazakii was well acknowledged prior to the taxonomic revision to the Cronobacter genus, which was based on DNA-DNA hybridisation, $16 \mathrm{~S}$ rDNA sequence analysis, and biotyping [5]. The earlier biotyping scheme was extremely useful in aiding the definition of the various Cronobacter species, especially due to the close genetic relationship of $C$. sakazakii and $C$. malonaticus which initially was regarded as a subspecies of C. sakazakii [4].

Nevertheless, phenotyping is in part subjective, and a DNA based scheme is preferred for its robustness. This study has used 7 loci for a MLST scheme for C. sakazakii and C. malonaticus. Strains were chosen to represent the diversity of C. sakazakii and C. malonaticus based on biotype, geographic and temporal distribution, and source (environmental, formula, clinical). The strains were from Europe, USA, Canada, Russia, New Zealand, Korea and China. The isolation dates ranged over 57 years from 1951 to 2008 .

As MLST uses multiple loci, a greater degree of variation and better resolution for MLSA and for inferring evolutionary and epidemiological relatedness can be obtained than by a single locus alone. Twelve sequence types of $C$. sakazakii were assigned. ST4 contained the largest number of strains, both clinical, infant formula, and milk powder isolates, from USA, Canada, Europe and Russia. The earli- 


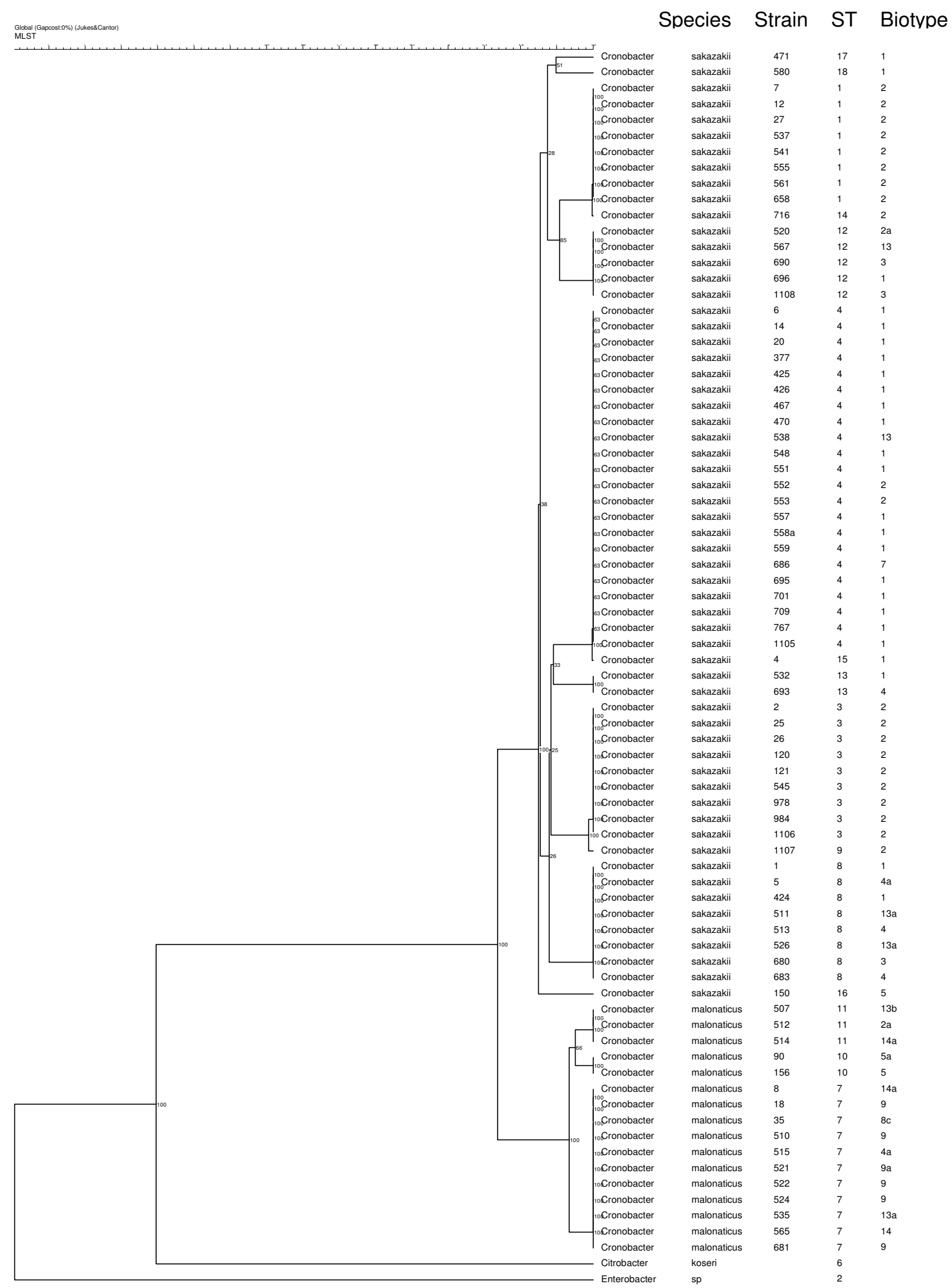

Figure I

Phylogenetic tree of concatenated nucleotide sequences from the seven loci, using the UPGMA method, Jukes-Cantor. Bootstrap values are shown for I,000 replicates. 
est isolate dates from 1951 and demonstrates the ubiquity of this sequence type. Many (18/22) of these strains were biotype 1 , which was previously shown to be the most numerous biotype (60/189) [3].

Previously Caubilla-Barron et al. [16] and Townsend et al. [20] reported on C. sakazakii infections in neonatal intensive care unit outbreak, which involved 4 pulsetypes. Only one pulsetype (PT2) was associated with all the deaths and therefore indicated that C. sakazakii strains may vary in their virulence potential. PT2 strains caused necrotizing enterocolitis (NEC), septicaemia, and meningitis. These strains were all in ST4. Other strains, associated with nonfatal NEC, neonatal colonisation, and infant formulas were in ST12, 13 and 14.

ST8 is of particular interest as 7/8 strains were clinical in origin, the eighth isolate being isolated from infant formula. These organisms isolated between 1977 and 2006 were from USA, Canada, France and the Czech Republic. ST8 also contains the C. sakazakii type strain (NCTC $11467^{\mathrm{T}}$, equivalent ATCC $29544^{\mathrm{T}}$ ) and interestingly the index strains for biotypes 1, 3 and 4 . Some of these strains have previously been studied by Pagotto et al. [33] and Postupa and Aldova [35]. ST(8) therefore merits further investigation, as it may represent a particularly virulent type of $C$. sakazakii strains.

Similarly ST7 in C. malonaticus was dominated (8/11) by clinical isolates, however this grouping may be biased as 5 clinical isolates $(510,515,521,522,524)$ were epidemiologically linked. There is also a predominance of biotype 9 in this sequence type, which may in part explain why that biotype was previously associated with clinical source; 10/13 strains [3].

The MLST scheme is openly available on the internet for other workers and will assist in the identification and discrimination of C. sakazakii and C. malonaticus based on DNA sequence in place of the far less reliable biotyping approach, which in isolation is essentially of no phylogenetic value and little epidemiological value. The role of biotyping in the identification and discrimination of $C$. sakazakii and $C$. malonaticus needs to be seriously reviewed. Even within the sample of isolates examined MLSA has already identified 1 or 2 STs which appear to be associated with enhanced virulence, and this may aid our understanding of the pathogenicity of this ubiquitous organism.

\section{Methods}

\section{Source of strains and biotyping}

Strains were chosen on the basis of their species, biotype, geographic and temporal distribution, source and clinical outcome (See Additional file 1). This included the type strains C. sakazakii NCTC $11467^{\mathrm{T}}$, and C. malonaticus CDC 1058-77T, biotype index strains, infant formula and clinical isolates, from Europe, USA, Canada, Russia, New Zealand, Korea and China, ranging from 1951 to 2008. The majority of these have associated published articles (See Additional file 1). Biotyping was as according to Iversen et al. [3].

\section{DNA isolation and PCR}

Genomic DNA was prepared using GenElute ${ }^{\mathrm{TM}}$ Bacterial Genomic DNA Kit (Sigma) and $1.5 \mathrm{ml}$ of overnight culture grown in TSB broth as per the manufacturer's instructions.

\section{Selection of MLST gene loci}

MLST loci were selected by comparing genome sequence data for C. sakazakii (strain ATCC BAA-894; http:// genome.wustl.edu), Cit. koseri (strain ATCC BAA-895; http://genome.wustl.edu) and Enterobacter sp. strain 638 http://www.jgi.doe.gov/ using the Artemis Comparison Tool (ACT) and the Double ACT program available at http://www.sanger.ac.uk/Software/ACT/ and http:// www.hpa-bioinfotools.org.uk/pise/double act.html, respectively.

\section{Primer design}

Amplification and nested sequencing primers for the MLST loci were then designed to conserved areas of these genes using Primer3 available at http://frodo.wi.mit.edu/ [36].

For each locus, primers were designed to have a similar melting temperature and were found to successfully amplify by PCR a panel of C. sakazakii and C. malonaticus strains (Table 1 and Additional file 1). Reaction conditions for all the primers were as follows: initial denaturation at $94^{\circ} \mathrm{C}$ for $2 \mathrm{~min} ; 30$ cycles of denaturation at $94^{\circ} \mathrm{C}$ for $1 \mathrm{~min}$, primer annealing at $58^{\circ} \mathrm{C}$ for $1 \mathrm{~min}$, extension at $72^{\circ} \mathrm{C}$ for $2 \mathrm{~min}$; followed by a final extension step of $72^{\circ} \mathrm{C}$ for $5 \mathrm{~min}$. Each $50 \mu \mathrm{l}$ amplification reaction mixture comprised $\sim 10$ ng chromosomal DNA, $10 \mu \mathrm{l}$ Q solution (Qiagen, Crawley, UK), 20 pmol forward and reverse primer, 1× PCR buffer (Qiagen) containing $1.5 \mathrm{mM}$ $\mathrm{MgCl}_{2}, 0.8 \mathrm{mM}$ deoxynucleotide triphosphates and 1.25 U Taq (Qiagen). The amplification product was then purified using MinElute UF plates (Qiagen) following the manufacturer's protocol before being used in a sequencing reaction.

\section{Multilocus sequence analysis}

Using the nested sequencing primers, nucleotide sequences were determined at least once on each DNA strand with BigDye Terminator Ready Reaction Mix v3.1 (PE Biosystems, Foster City, US) under standard sequencing conditions according to the manufacturer's protocol. 
Unincorporated dye terminators were removed by precipitation with 95\% alcohol. The reaction products were separated and detected on an ABI PRISM genetic analyser 3100 (PE Biosystems) using a standard sequencing module with a Performance Optimised Polymer and $5 \mathrm{~cm}$ array. The sequences from both strands of a given locus of the same isolate were aligned, trimmed to the desired length and edited using SeqMan II (DNA Star software, Madison, US).

\section{Allele and Sequence Type designation}

Arbitrary allelic numbers were assigned to each unique allele for a given locus. After sequencing and assigning allele types to all seven loci each isolate was then designated by a combination of seven numbers called an allelic profile that represented a sequence type (ST) for that particular isolate (eg. ST1). A novel sequence type (ST) designation was given to each isolate with a unique allelic profile while subsequent isolates with an identical allelic profile were assigned the same ST identifier and considered to be isogenic strains as they were indistinguishable at all seven loci. All alleles within the MLST scheme were in frame, to aid with analysis.

\section{Linkage analysis}

Linkage analysis was carried out by using the index of association $\left(I_{A}\right)$, as defined previously [37]. We examined whether alleles were randomly associated, that is, at linkage equilibrium, indicating a freely recombining population, or non-randomly associated, that is, at linkage disequilibrium, implying a clonal population structure. If there is linkage equilibrium, i.e., a random association between alleles of different loci, $I_{A}=0$. If $I_{A}$ is significantly different from 0 , it indicates that recombination has been rare or absent and that the population has a clonal structure [34].

\section{Authors' contributions}

$\mathrm{AB}$ designed and carried out the MLST, assisted by EK. JC, ML, GM and CD provided technical expertise. Thanks to Edward Hurrell for additional strain biotyping. AB and SF wrote the manuscript. SF managed the project. All authors read and approved the final manuscript.

\section{Additional material}

\section{Additional file 1}

MLST analysis of the Cronobacter isolates showing their source, geographic location and species. The data provided shows the spacial, temporal and source of strains used in this study, and reference where the strains have been used in previous publications.

Click here for file

[http://www.biomedcentral.com/content/supplementary/14712180-9-223-S1.DOC]

\section{Acknowledgements}

The authors thank Nottingham Trent University, Micropathology Ltd and the Medical Research Fund for the funding of this study. We also thank collaborators for their strain donations, especially Dr Harry Muytjens, Dr Ivo Safarík (Czech Academy of Sciences, Czech Republic), Prof J. Farber (Health Canada) and Prof J. Park (Kyungwon University, Korea).

\section{References}

I. Farmer JJ III, Asbury MA, Hickman FW, Brenner DJ, The Enterobacteriaceae study group: Enterobacter sakazakii: a new species of "Enterobacteriaceae" isolated from clinical specimens. Intl J System Bacteriol 1980, 30:569-584.

2. Iversen C, Waddington M, On SLW, Forsythe S: Identification and phylogeny of Enterobacter sakazakii relative to Enterobacter and Citrobacter. J Clin Microbiol 2004, 42:5368-5370.

3. Iversen C, Waddington M, Farmer JJ III, Forsythe S: The biochemical differentiation of Enterobacter sakazakii genotypes. BMC Microbiology 2006, 6:94.

4. Iversen C, Lehner A, Mullane N, Bidlas E, Cleenwerck I, Marugg J, Fanning S, Stephan R, Joosten H: The taxonomy of Enterobacter sakazakii: proposal of a new genus Cronobacter gen. nov. and descriptions of Cronobacter sakazakii comb. nov. Cronobacter sakazakii subsp. sakazakii, comb. nov., Cronobacter sakazakii subsp. malonaticus subsp. nov., Cronobacter turicensis sp. nov., Cronobacter muytjensii sp. nov., Cronobacter dublinensis sp. nov. and Cronobacter genomospecies I. BMC Evol Biol 2007, 7:64.

5. Iversen C, Mullane N, McCardell B, Tall BD, Lehner A, Fanning S, Stephan $\mathrm{R}$, Joosten $\mathrm{H}$ : Cronobacter gen. nov., a new genus to accommodate the biogroups of Enterobacter sakazakii, and proposal of Cronobacter sakazakii gen. nov., comb. nov., Cronobacter malonaticus sp. nov., Cronobacter turicensis sp. nov., Cronobacter muytjensii sp. nov., Cronobacter dublinensis sp. nov., Cronobacter genomospecies I, and of three subspecies, Cronobacter dublinensis subsp. dublinensis subsp. nov., Cronobacter dublinensis subsp. lausannensis subsp. nov. and Cronobacter dublinensis subsp. lactaridi subsp. nov. Intl J System Evol Microbiol 2008, 58: I442-1447.

6. Food and Agriculture Organization-World Health Organization (FAO-WHO): Joint FAO/WHO workshop on Enterbacter sakazakii and other microorganisms in powdered infant formula, Geneva, 2-5 February, 2004. 2004 [http://www.who.int/food safety/publications/feb 2004/en/print.html].

7. Food and Agriculture Organization-World Health Organization (FAO-WHO): Enterobacter sakazakii and Salmonella in powdered infant Formula. Second Risk Assessment Workshop. 16-20th January. WHO Rome, Italy 2006 [http://www.who.int/foodsafety/publi cations/micro/mral0/en/index.html].

8. Forsythe S: Enterobacter sakazakii and other bacteria in powdered infant milk formula. Maternal Child Nutr 2005, I:5I-58.

9. Iversen C, Forsythe SJ: Risk profile of Enterobacter sakazakii, an emergent pathogen associated with infant milk formula. Trends in Food Sci Technol 2003, II :443-454.

10. Friedemann M: Enterobacter sakazakii in food and beverages (other than infant formula and milk powder). Intl J Food Microbiol 2007, I 1 6: I-10.

1I. Food and Agriculture Organization-World Health Organization (FAO-WHO): Enterobacter sakazakii (Cronobacter spp.) in powdered follow-up formulae. Washington, D.C 2008 [http:// www.who.int/foodsafety/publications/micro/MRA followup.pdf]. Date last accessed 08/05/09

12. van Acker J, de Smet F, Muyldermans G, Bougatef A, Naessens A, Lauwers S: Outbreak of necrotizing enterocolitis associated with Enterobacter sakazakii in powdered milk formula. J Clin Microbiol 200I, 39:293-297.

13. Himelright I, Harris E, Lorch V, Anderson M: Enterobacter sakazakii infections associated with the use of powdered infant formula-Tennessee, 200I. JAMA 2002, 287:2204-2205.

14. Jarvis C: Fatal Enterobacter sakazakii infection associated with powdered infant formula in a neonatal intensive care unit in New Zealand. Am J Infect Control 2005, 23:el 9.

15. Coignard B, Vaillant V, Vincent J.-P, Leflèche A, Mariani-Kurkdjian P, Bernet C, L'Hériteau F, Sénéchal H, Grimont P, Bingen E, Desenclos $J-C$ : Infections sévères à Enterobacter sakazakii chez des nou- 
veau-nés ayant consommé une préparation en poudre pour nourrissons, France, octobre-décembre 2004. Bull Epidémiol Hebdomadaire 2006, 2-3:10-13 [http://www.invs.sante.fr/beh/2006/ 02 03/beh 0203 2006.pdf].

16. Caubilla-Barron J, Hurrell E, Townsend S, Cheetham P, Loc-Carrillo C, Fayet $O$, Prere M-F, Forsythe S): Genotypic and phenotypic analysis of Enterobacter sakazakii strains from an outbreak resulting in fatalities in a neonatal intensive care unit in France. J Clin Microbiol 2007, 45:3979-3985.

17. International Commission on Microbiological Specifications for Foods: Microorganisms in foods 7. Microbiological testing in food safety management. Kluwer Academic/Plenum Publishers, New York, NY; 2002

18. WHO: 'Safe preparation, storage and handling of powdered infant formula guidelines', and associated specialised documents for various care situations. 2007 [http://www.who.int/ foodsafety/publications/micro/pif2007/en/index.html]

19. Townsend SM, Hurrell E, Gonzalez-Gomez I, Lowe J, Frye JG, Forsythe S, Badger JL: Enterobacter sakazakii invades brain capillary endothelial cells, persists in human macrophages influencing cytokine secretion and induces severe brain pathology in the neonatal rat. Microbiology 2007, I 53:3538-3547.

20. Townsend S, Hurrell E, Forsythe S): Virulence studies of Enterobacter sakazakii isolates associated with a neonatal intensive care unit outbreak. BMC Microbiol 2008, 8:64

21. Dauga C: Evolution of the gyrB gene the molecular phylogeny of Enterobacteriaceae: a model molecule for molecular systematic studies. Intl J Syst Evol Microbiol 2002, 52:53 I-547.

22. Konstantinidis $\mathrm{KT}$, Ramette $\mathrm{A}$, Tiedje JM: Toward a more robust assessment of intraspecies diversity, using fewer genetic markers. Appl Environ Microbiol 2006, 72:7286-7293.

23. Diancourt L, Passet V, Verhoef J, Grimont PA, Brisse S: Multilocus sequence typing of Klebsiella pneumoniae nosocomial isolates. J Clin Microbiol 2005, 43:4I78-82.

24. Wirth T, Falush D, Lan R, Colles F, Mensa P, Wieler LH, Karch H, Reeves PR, Maiden MC, Ochman H, Achtman M: Sex and virulence in Escherichia coli: an evolutionary perspective. Mol Microbiol 2006, 60: I|36-|| I I.

25. Kuhnert P, Korczak BM, Stephan R, Joosten H, Iversen C: Phylogeny and prediction of genetic similarity of Cronobacter and related taxa by multilocus sequence analysis (MLSA). Intl J Food Microbiol 2009. Electronic copy available ahead of print

26. Muytjens HL, Roelofs-Willemse H, Jaspar GH: Quality of powdered substitutes for breast milk with regard to members of the family Enterobacteriaceae. I Clin Microbiol I 988, 26:743-746.

27. Muytjens HL, Zanen HC, Sonderkamp HJ, Kollée LA, Wachsmuth K Farmer J]: Analysis of eight cases of neonatal meningitis and sepsis due to Enterobacter sakazakii. J Clin Microbiol 1983, 18:115-120.

28. Hurrell E, Kucerova E, Loughlin M, Caubilla-Barron J, Hilton A, Armstrong R, Smith C, Grant J, Shoo S, Forsythe S: Enteral feeding tubes as loci for colonisation by members of the Enterobacteriaceae. BMC Inf Dis 2009, 9:46.

29. Chap J, Jackson P, Siqueira R, Gaspar N, Quintas C, Park J, Osaili T, Shaker S, Jaradat Z, Hartantyo SHP, Abdullah SN, Estuningsih S, Forsythe SJ: International survey of Cronobacter sakazakii and other Cronobacter spp. in follow up formulas and infant foods. Intl J Food Microbiol 2009. Electronic copy available ahead of print

30. Aldová $E$, Hausner O, Postupa R: Tween esterase activity in Enterobacter sakazakii. Zentralblatt fuer Bakteriologie Mikrobiologie und Hygiene Series A 1983, 256:103-108.

31. Caubilla-Barron J, Forsythe S: Dry stress and survival time of Enterobacter sakazakii and other Enterobacteriaceae. J Food Protect 2007, 70:2111-7.

32. Townsend S, Caubilla-Barron J, Loc-Carrillo C, Forsythe S: The presence of endotoxin in powdered infant formula milk and the influence of endotoxin and Enterobacter sakazakii on bacterial translocation in the infant rat. Food Microbiol 2007, 24:67-74.

33. Pagotto FJ, Nazarowec-White M, Bidawid S, Farber JM: Enterobacter sakazakii: infectivity and enterotoxin production in vitro and in vivo. I Food Protect 2003, 66:370-377.

34. Smith JM, Smith NH, O'Rourke M, Spratt BG: How clonal are bacteria? Proc Natl Acad Sci USA 1993, 90:4384-8.
35. Postupa R, Aldová E: Enterobacter sakazakii: a Tween-80 esterase-positive representative of the genus Enterobacter isolated from powdered milk specimens. J Hyg Epidemiol Microbiol Immunol 1984, 28:435-440.

36. Rozen S, Skaletsky HJ: Primer3 on the WWW for general users and for biologist programmers. In Bioinformatics Methods and Protocols: Methods in Molecular Biology Edited by: Krawetz S, Misener S. Humana Press, Totowa, NJ; 2000:365-386.

37. Jolley KA, Feil EJ, Chan MS, Maiden MCJ: Sequence type analysis and recombinational tests (START). Bioinformatics 200I, I7:|230-|23I.
Publish with Biomed Central and every scientist can read your work free of charge

"BioMed Central will be the most significant development for disseminating the results of biomedical research in our lifetime. "

Sir Paul Nurse, Cancer Research UK

Your research papers will be:

- available free of charge to the entire biomedical community

- peer reviewed and published immediately upon acceptance

- cited in PubMed and archived on PubMed Central

- yours - you keep the copyright 